\title{
$\longrightarrow$ www.czasopisma.pan.pl \\ Selected Technological Properties of Liquid Ceramic Slurries Used to Produce Moulds in the Replicast cs Technology
}

\author{
R. Kaczorowski *, P. Just, T. Pacyniak \\ Department of Materials Engineering and Production Systems, Lodz University of Technology, \\ ul. Stefanowskiego 1/15, 90-924 Łódź, Polska \\ * Corresponding author: E-mail address: rafal.kaczorowski@p.lodz.pl
}

Received 19.04.2017; accepted for printing 03.08.2017

\begin{abstract}
The study discusses the issues connected with the production of thin-walled ceramic slurry in the replicast cs technology. In the ceramic mould production process, a special role is played by the liquid ceramic slurry used to produce the first layer of the mould. The study examines selected technological properties of liquid ceramic slurries used to produce moulds in the replicas cs technology. The ceramic slurries for the tests were prepared based on the binders Ludox Px30 and Sizol 030, enriched with Refracourse flour. The wettability of the pattern's surface by the liquid ceramic slurry and the dependence of the apparent viscosity on the ceramic flour content in the mixture were determined. The wettability of the pattern surface by the liquid ceramic slurry was determined based on the measurement of the wetting angle. The angle was determined by means of an analysis of the computer image obtained with the use of a CDC camera.
\end{abstract}

Keywords: Innovative materials and casting technologies, Precision casting, Thin-walled ceramic moulds, Apparent viscosity, Replicast cs

\section{Introduction}

For several centuries, among the many casting technologies, the human has been accompanied in his civilizational and cultural development by the lost mould method, also called the lost wax method [1]. Already in the time before Christ, it was used to make artistic goods, especially decorative ones. Its progress ran differently in different parts of the worlds and it can be recreated only to a certain degree, based on the museum exhibits, which are now priceless.

The preparation of ceramic moulds is the basic step in the production of casts according to the lost mould method [4]. The type of the mould material, the technology of the mould preparation and the mould reinforcing treatment determine the quality of the produced casts and their properties [7]. The type and parameters of the applied moulding materials as well as the technique of the mould preparation decide about their quality and thus that of the casts, and affect the economical indexes [2-4]. The basic stages of the mould preparation process are the following technological procedures:

- $\quad$ Preparation of pattern sets from wax pattern slurries;

- Preparation of liquid ceramic slurries;

- $\quad$ Preparation of ceramic layers of the mould;

- $\quad$ Drying of particular mould layers;

- Melting of the patterns in the moulds;

- Annealing of the ceramic moulds.

In the process of preparing the ceramic moulds according to the lost mould method, a special role is played by the liquid 
ceramic slurry used to make the first layer of the mould [3-6]. This type of slurry is required to characterize in:

- Good wettability on the pattern set-liquid boundary, which determines the quality of the produced casts;

- Homogeneity - the presence of caked ceramic materials is unacceptable;

- $\quad$ Long-term durability, i.e. constant viscosity in the function of time.

The quality of the liquid ceramic slurry is affected by such factors as:

- Chemical composition and granularity of the ceramic material, hydrogen ion exponent, $\mathrm{pH}$ of the binder;

- Ratio of the amount of binder and ceramic material;

- $\quad$ Parameters of the mixing process.

\section{Test methodology}

The experiments were performed at the Department of Materials Engineering and Production Systems of Lodz University of Technology.

The ceramic slurries for the tests were prepared based on the binders Ludox Px30 and Sizol 030, enriched with Refracourse flour. The weight ratio of the binder and the flour was: $(1 / 1,4$; $1 / 1,5 ; 1 / 1,6 ; 1 / 1,7)$ for Ludox and $(1 / 1,5 ; 1 / 1,6)$ for Sizol. A surface active agent in the form of Rokafenol N8 was added to the mixtures. The mixtures with the addition of the surface active agent - Rokafenol N8 - were prepared for its optimal content, i.e. $0,2 \%$ wt. in respect of the binder. This value was determined from the performed preliminary tests, where it was established that a higher content of Rokafenol does not significantly lower the surface tension of the mixture and causes its excessive foaming during mixing, which results in the occurrence of air bubbles on the coating applied on the pattern.

For the preparation of the liquid ceramic slurries, laboratory scales and a mechanical mixer were used.

\subsection{Determination of the pattern surface wettability by the liquid ceramic slurry}

The wettability of the pattern surface by the liquid ceramic slurry was determined based on the measurement of the wetting angle. The angle was determined by means of an analysis of the computer image obtained with the use of a CDC camera. The subject of the measurement was a drop of the liquid ceramic slurry applied on the surface of the measurement sample made of a material used for patterns in the replicast cs technology, with the consideration of the roughness of such a pattern.

The wetting angle was measured on three different surfaces:

A - a polystyrene profile made by means of injection moulding (surface roughness $\mathrm{Ra} 1$ ), $\mathrm{B}$ - a profile made of polystyrene extruded on a surface not subjected to cutting (surface roughness $\mathrm{Ra} 11$ ) and $\mathrm{C}$ - a profile made of polystyrene extruded on a surface subjected to cutting with a hot wire (surface roughness $\mathrm{Ra} 34$ ).

The test bench for the wetting angle measurements is presented in Figure 1. The wetting angle was determined by way of dimensioning the angle between the sample substrate and the tangent to the arc of the drop's cap.

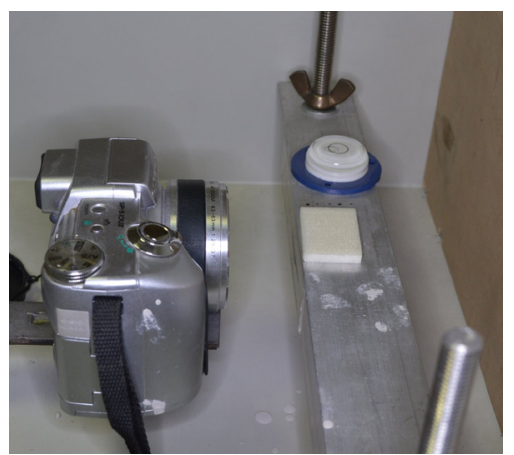

Fig. 1. Test bench for the measurements of the pattern's wetting angle

\subsection{Dependence of the apparent viscosity on the ceramic flour content in the liquid ceramic slurry}

The determination of the dependence of the apparent viscosity on the content of the ceramic flour makes it possible to establish identical apparent viscosities of liquid ceramic slurries differing in the chemical and/or physical content.

The dynamic viscosity was measured by means of the Brookfield DV1 viscometer, with the use of the R02 spindle.

The measurement of the dynamic viscosity of the ceramic mixtures on the Brookfield viscometer is quite difficult, as the ceramic mixtures undergo rapid sedimentation. The flour is rapidly deposited on the spindle; during the measurement, the viscosity first increased, reaching its maximal value, and then decreased in time. That is why the viscosity measurement was read for the maximal value after temporary stabilization.

In the brief viscosity measurements, an outflow cup. The determination consisted in a measurement of the increase of the apparent viscosity of the ceramic slurry, measured with a Ford type cup (Fig. 2), together with the increase of the content of the ceramic flour in the liquid ceramic slurries. In the measurement, a Ford type cup with the outflow diameter $=6 \mathrm{~mm}$ was used.

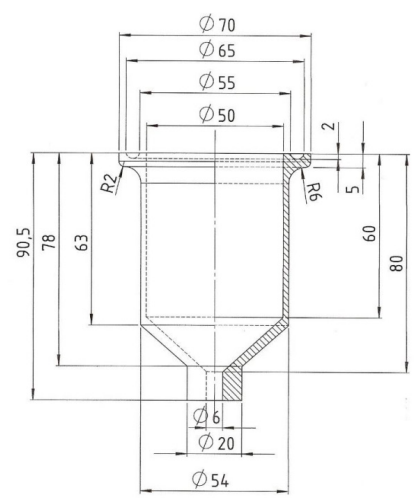

Fig. 2. Ford type cup - outflow diameter $6 \mathrm{~mm}$ 
In order to recalculate the time of the outflow from the cup into the kinematic viscosity, a series of measurements of the viscosity of the ceramic mixtures were performed by means of the Brookfield viscometer, where the mixture density was measured next to the dynamic viscosity.

The relation between the kinematic and dynamic viscosity was determined from the following equation:

$\vartheta=\frac{\mu}{\rho}\left[\frac{m^{2}}{s}\right]$

where:

$\vartheta$ - kinematic viscosity, $\mathrm{m}^{2} / \mathrm{s}$,

$\mu$ - dynamic viscosity, $\mathrm{Pa} \cdot \mathrm{s}$,

$\rho$ - density, $\mathrm{kg} / \mathrm{m}^{3}$.

\section{Test results}

\subsection{Determination of the pattern surface wettability by the liquid ceramic slurry}

Fig. 3 shows the effect of the type of substrate and the composition of the Sizol-based mixture without a surface active agent on the wettability. It can be inferred from the figure that the wettability is mainly affected by the type of the substrate.

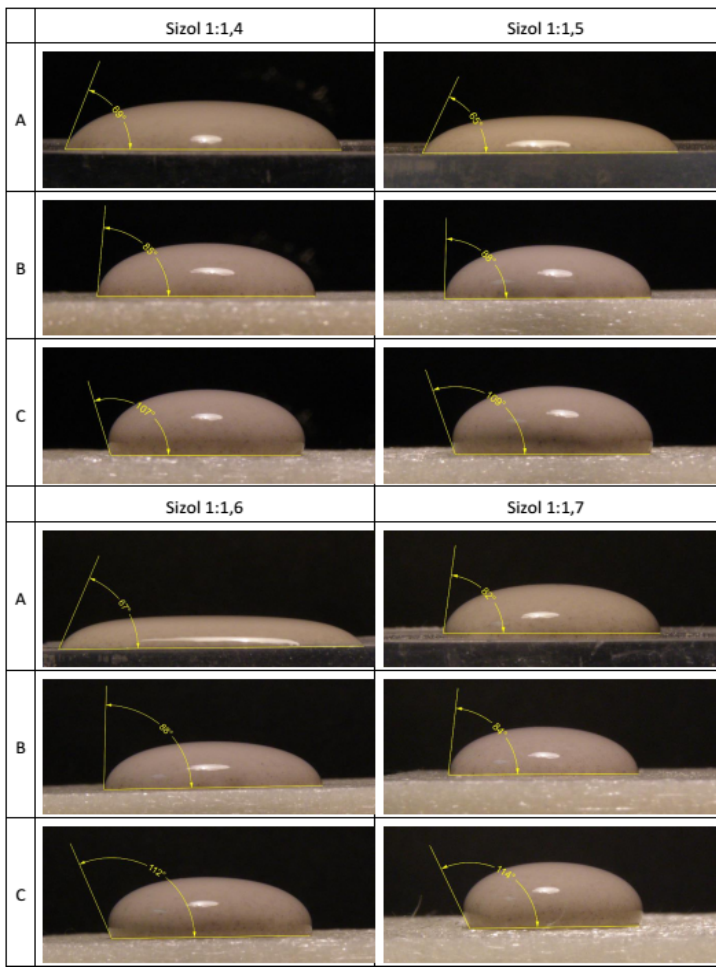

Fig. 3. Effect of the substrate type and the composition of a Sizol-based mixture without a surface active agent on wettability
The smallest wetting angle is obtained for substrate A (polystyrene profile made by the injection method /die stamping /), that is for the substrate with the lowest roughness. The angle is within the range of $60-80^{\circ}$. The higher the surface roughness, the larger the wetting angles. For substrate B (polystyrene extruded on a surface not subjected to cutting /XPS/), the wetting angles are close to the right angle, whereas for substrate $\mathrm{C}$ (polystyrene extruded on a surface subjected to cutting with a hot wire /cut XPS /), the angles equal about $110^{\circ}$.

After Rokafenol N8 was added to the ceramic mixture based on Sizol, the surface tension was significantly reduced. The wetting angle decreased significantly, not exceeding $50^{\circ}$ on any of the substrates, which has been presented in Fig. 4.

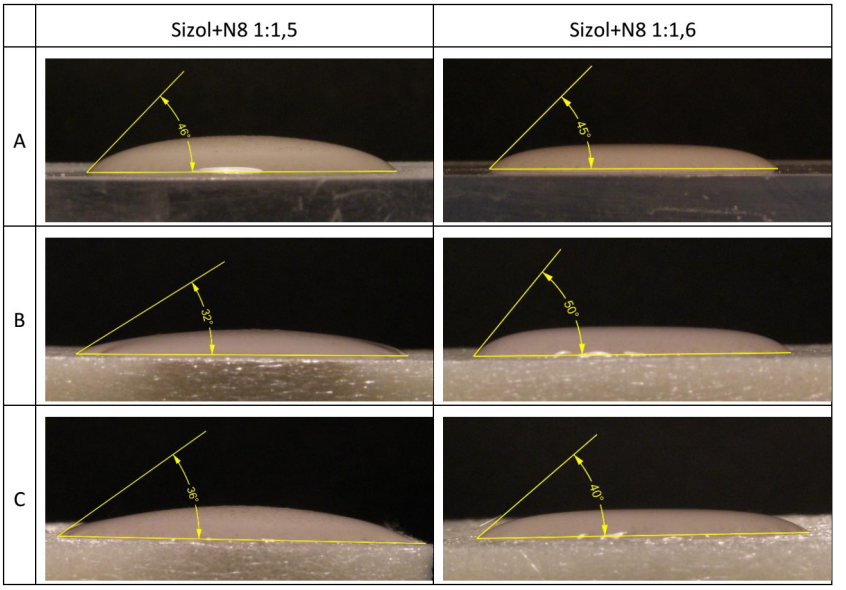

Fig. 4. Effect of the substrate type and the composition of a Sizolbased mixture with a Rokafenol N8 addition on wettability

The results of the tests on the surface wettability by the ceramic mixture with the Ludox binder were very close to those in the case of Sizol, and so, Figure 5 shows only a comparison of the wetting angle of the mixtures based on Ludox of identical flowing powers equaling $30 \mathrm{~s}$, with and without a surface active agent.

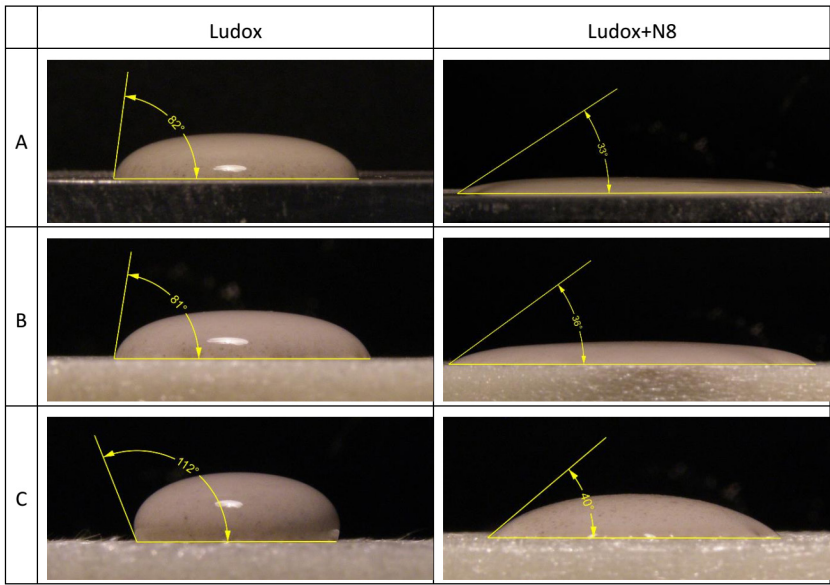

Fig. 5. Comparison of the wettability of a ceramic mixture based on Ludox PX30 with and without a Rokafenol N8 addition 
The wetting angles significantly decreased (to $30-40^{\circ}$ ) after Rokafenol N8 was added.

\subsection{Dependence of the apparent viscosity on the ceramic flour content and the surface active agent addition in the liquid slurry}

The results of the dynamic viscosity measurements performed by means of the Brookfield viscometer and an outflow cup (Fig. 2) are presented in Table 1.

Table 1.

Dynamic viscosity and flowing power of the examined ceramic slurries

\begin{tabular}{|c|c|c|c|c|c|}
\hline Lp. & $\begin{array}{l}\text { Binder } \\
\text { type }\end{array}$ & $\begin{array}{l}\text { Binder- } \\
\text { flour } \\
\text { weight } \\
\text { ratio }\end{array}$ & $\begin{array}{c}\text { Surface } \\
\text { active agent }\end{array}$ & $\begin{array}{l}\text { Dynamic } \\
\text { viscosity } \\
\mu, \mathrm{mPa} \cdot \mathrm{s}]\end{array}$ & $\begin{array}{c}\text { Flowing } \\
\text { power (time } \\
\text { of outflow } \\
\text { from cup), s }\end{array}$ \\
\hline 1 & \multirow{8}{*}{$\begin{array}{c}\text { Sizol } \\
030\end{array}$} & \multirow[b]{2}{*}{$1: 1,4$} & - & 175 & 13 \\
\hline 2 & & & $\begin{array}{c}\text { Rokafenol } \\
\text { N8 }\end{array}$ & 195 & 14 \\
\hline 3 & & \multirow[b]{2}{*}{$1: 1,5$} & - & 234 & 17 \\
\hline 4 & & & $\begin{array}{c}\text { Rokafenol } \\
\text { N8 }\end{array}$ & 267 & 21 \\
\hline 5 & & \multirow[b]{2}{*}{$1: 1,6$} & - & 362 & 25 \\
\hline 6 & & & $\begin{array}{c}\text { Rokafenol } \\
\text { N8 }\end{array}$ & 419 & 29 \\
\hline 7 & & \multirow[b]{2}{*}{$1: 1,7$} & - & 460 & 33 \\
\hline 8 & & & $\begin{array}{c}\text { Rokafenol } \\
\text { N8 }\end{array}$ & 515 & 37 \\
\hline 9 & \multirow{6}{*}{$\begin{array}{l}\text { Ludox } \\
\text { PX30 }\end{array}$} & \multirow[b]{2}{*}{$1: 1,5$} & - & 236 & 17 \\
\hline 10 & & & $\begin{array}{c}\text { Rokafenol } \\
\text { N8 }\end{array}$ & 352 & 25 \\
\hline 11 & & \multirow[b]{2}{*}{$1: 1,6$} & - & 325 & 22 \\
\hline 12 & & & $\begin{array}{c}\text { Rokafenol } \\
\text { N8 }\end{array}$ & 420 & 30 \\
\hline 13 & & \multirow[b]{2}{*}{$1: 1,7$} & - & 542 & 38 \\
\hline 14 & & & $\begin{array}{c}\text { Rokafenol } \\
\text { N8 }\end{array}$ & 570 & 42 \\
\hline
\end{tabular}

It can be inferred from the data in Table 1 that adding a surface active agent in the form of Rokafenol N8 causes an increase of the flowing power of the ceramic mixture. This increase is higher for the mixture with the Ludox binder.

The results of the measurement of the dynamic viscosity and the flowing power of the ceramic mixtures are presented in Table 2 .

By means of the equation of the trend line presented in Figure 6, based on the outflow densities measured with the use of a Ford type cup, it is possible to determine the kinematic viscosity, which facilitates the measurement of density in liquid ceramic slurries.
Table 2.

Dynamic viscosities and densities of the examined ceramic mixtures

\begin{tabular}{cccc}
\hline $\begin{array}{c}\text { Time of } \\
\text { outflow } \\
\text { from cup } \mathrm{t}, \mathrm{s}\end{array}$ & $\begin{array}{c}\text { Dynamic } \\
\text { viscosity } \mu, \\
\mathrm{mPa} \cdot \mathrm{s}\end{array}$ & $\begin{array}{c}\text { Density } \rho, \\
\mathrm{kg} / \mathrm{m}^{3}\end{array}$ & $\begin{array}{c}\text { Kinematic } \\
\text { viscosity } \mathrm{v}, \\
10^{-3} \mathrm{~m}^{2} / \mathrm{s}\end{array}$ \\
\hline 13 & 175 & 1760 & 99 \\
\hline 14 & 195 & 1770 & 110 \\
\hline 17 & 234 & 1775 & 132 \\
\hline 21 & 305 & 1810 & 169 \\
\hline 23 & 336 & 1765 & 190 \\
\hline 25 & 352 & 1802 & 195 \\
\hline 26 & 360 & 1794 & 201 \\
\hline 29 & 419 & 1830 & 229 \\
\hline 33 & 460 & 1850 & 249 \\
\hline 37 & 515 & 1838 & 280 \\
\hline
\end{tabular}

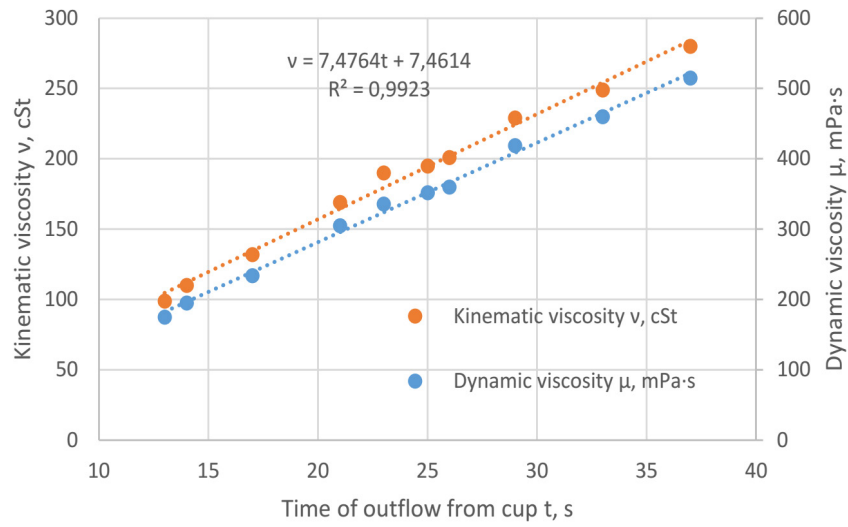

Fig. 6. Dependence of the kinematic and dynamic viscosity on the outflow density

\section{Conclusions}

On the basis of the obtained test results, we can draw the following conclusions:

- The wettability of the pattern surface by liquid ceramic slurries is mainly affected by the type of substrate.

- The smallest wetting angle was obtained for the substrate with the lowest roughness (polystyrene profile made by the injection moulding method/die stamping/). The angle is within the range of $60-80^{\circ}$. The higher the surface roughness, the larger the wetting angles.

- $\quad$ The surface wettabilities in the case of the ceramic mixture with the Ludox binder were very close to those with Sizol.

- The addition of a surface active agent in the form of Rokafenol N8 increases the flowing power of the ceramic mixture. This increase is the highest for the mixtures with the Ludox binder. 


\section{Acknowledgements}

The research has been realized within the Project no. POIR.01.01.01-00-0552/15 as part of the competition $1 / 1.1 .1 / 2015$, within the Smart Growth Operational Program, Activities 1.1 „R\&D projects for enterprises”, Sub-activities 1.1.1 „Industrial and development research realized by enterprises."

Project title: „Development of an innovative device applying a unique technology of a fast production of laminar ceramic moulds for precision casting."

The subject area of the scientific studies conducted at our unit: Industrial studies in the scope of the development of a technology of a fast production of thin-walled ceramic moulds used for precision casting.

\section{References}

[1] Sharman, S.G. (1984). The Replicast CS Process. Foundry Trade Journal.
[2] Adamczyk, A., Karwiński, A., Para, G. (1999). Characteristics of physicochemical binders and liquid ceramic slurry used in foundry. Eyd. Instytutu Odlewnictwa, Kraków.

[3] Karwiński, A., Adamczyk, A. \& Para, G. (2001). Phisicochemical and Technological Properties of Ceramic Slurries in investment casting. Acta Metallurgica Slovaca.

[4] Taylor, P.R. (1979). Problems of Primary lury quality control for ceramic shell moulds, International Simposium of Investment Casting, Tabor.

[5] Karwiński, A. Stachańczyk, J. (1995). Ceramic Slurry and first mould coat - a concept of estimation. 8th International Simposium of Investment Casting. PRECAST'95, Brno, Czechy.

[6] Haratym, R. (1973). Influence of some technological parameters on the dimensional accuracy of castings made by investment casting. Kraków: Wyd STOP Instytut Odlewnictwa.

[7] Pisarek, B.P., Rapiejko, C., Święcik, R. \& Pacyniak, T. (2015). Effect Inhibitor Coating of a Ceramic Mould on the Surface Quality of an AM60 Alloy Cast with $\mathrm{Cr}$ and V. Archives of Foundry Engineering. 15(3), 51-56. 